\title{
A APRENDIZAGEM NO CONTEXTO DAS TECNOLOGIAS: UMA REFLEXÃO PARA OS DIAS ATUAIS
}

\author{
Morgana Scheller, IF Catarinense - Rio do Sul/PUCRS, morgana@ifc-riodosul.edu.br \\ Lori Viali, PUCRS/UFRGS, viali@pucrs.br \\ Regis Alexandre Lahm, PUCRS, lahm@pucrs.br
}

\begin{abstract}
Resumo: Este artigo apresenta uma análise reflexiva de três teorias que podem ser utilizadas no contexto de ensino e de aprendizagem na era digital. Para tanto, de posse das concepções de aprendizagem de David Ausubel, Seymour Papert e George Siemens, traçou-se um paralelo entre as teorias na busca de semelhanças e diferenças entre elas, explicitando uma reflexão para a aprendizagem no contexto educacional na era digital. A análise permitiu verificar que em uma reflexão conjunta, a aprendizagem deve ocorrer formal e informalmente por meio de conexões estabelecidas nas redes em que o estudante motivado, constantemente estabelece relações com o que é potencialmente significativo. Trata-se de um processo contínuo, frequentemente atualizado, ocorrendo em um contexto de interação e de forma colaborativa, sendo o sujeito ativo em sua aprendizagem.
\end{abstract}

Palavras-chave: Teorias de aprendizagem. Tecnologias. Aprendizagem na era digital.

\section{LEARNING IN THE CONTEXT OF TECHNOLOGY: A REFLEXION TO THE PRESENT DAY}

\begin{abstract}
This paper introduces a reflexive analysis about three theories that can be used in the context of teaching and learning in the digital age. For this purpose, in possession of the conceptions of learning from David Ausubel, Seymour Papert and George Siemens, a parallel between the theories has been drawn, in the search for similarities and differences between them, explaining a reflection for learning in educational contexts in the digital age. The analysis has shown that taking into consideration the ideas of the three authors, learning must occur both formally and informally through established connections in networks where the motivated student, constantly establish relationships with what is potentially significant. This is a continuous and constantly updated process, occurring in a context of interaction and collaboration, with the student and the subject of his/her learning.
\end{abstract}

Keywords: Theories of learning. Technologies. Learning in the digital age.

\section{INTRODUÇÃO}

Nos últimos 30 anos as Tecnologias de Informação e Comunicação (TIC) estão sendo objeto de pesquisas e utilizadas num ritmo cada vez mais intenso na área educacional. Os estudos têm gerado significativa produção a respeito da utilização e dos recursos que elas colocam a disposição. Entre eles situam-se aqueles relacionados ao contexto educacional, considerando que o que se defendia em termos de tecnologias no início daquele período, provavelmente não é considerado o mais adequado nos dias atuais, devido à chegada e a rápida difusão da tecnologia digital. As constantes modificações ocorridas ao longo destas três décadas fizeram com que se repensasse a maneira como o ser humano concebe a tecnologia e aprende hoje, na era digital.

No início da década de 1990, no Brasil, a teoria de aprendizagem em destaque e com maior ênfase na educação era o Construtivismo cognitivo do biólogo suíço Jean William Fritz Piaget (1896-1980) e, iniciavam-se as discussões a respeito da teoria 
sócio-histórica e cultural do psicólogo russo Lev Semenovitch Vygostky (1896-1934), o sócio interacionismo, também denominado de Construtivismo Social. Essas teorias foram elaboradas numa época desprovida das denominadas "tecnologias", num momento em que a aprendizagem não sofria o impacto destas. $\mathrm{O}$ processo ensino aprendizagem então existente contava com apoio tecnológico do quadro (negro) e giz, mimeógrafo, gravador, retroprojetor, entre outros que são ainda presentes, como livro, caderno, vídeo e calculadora, por exemplo.

Várias dessas tecnologias não são mais utilizadas na atualidade, ao passo que várias outras surgiram, enriquecendo os recursos tecnológicos disponíveis. A explosão tecnológica permitiu o avanço de inúmeras áreas, sendo acessível a população direta ou indiretamente, modificando o comportamento e as relações sociais. Algumas dessas mudanças são percebidas nos espaços escolares, os quais não conseguiram, na mesma velocidade do avanço tecnológico, modelar-se ao estudante da era digital. De acordo com Prensky (2001, p. 2), “os estudantes de hoje não são mais as mesmas pessoas para as quais nosso sistema educacional foi desenvolvido”, e esta afirmação deve ser levada em consideração ao se pensar nos modelos educacionais aos quais as instituições de ensino de hoje se servem. O método como fomos ensinados não serve mais para ser utilizado com nossos estudantes. Os professores, na maioria, foram pegos pela revolução digital enquanto que os seus estudantes já nasceram na mesma.

Decorrido três décadas os estudos constatam que as formas como os estudantes da era digital aprendem são diferentes e que os professores não utilizam uma linguagem nova para facilitar a aprendizagem (Prensky, 2001). Como enfrentar esse problema? Como aprender numa era em que o excesso de informação predomina? Como levar o estudante a construir o seu saber, indo além dos fatos e informações?

Buscando compreender como os estudantes (nativos digitais) de hoje pensam e processam as informações, transformando-as em conhecimento, várias pesquisas foram e estão sendo elaboradas. Papert (2008, 1985, 1980), Siemens (2003, 2004 e 2008) e Downes $(2005,2007)$ tem se destacado no âmbito desta discussão.

Papert (2008) sugere uma adaptação das teorias de aprendizagem e propõe uma teoria face às implicações inerentes a utilização de tecnologia no ensino. Sua proposta, o construcionismo, defende que a aprendizagem é mais eficaz quando se constroem objetos tangíveis ou por meio de imagens. George Siemens (2004) desenvolveu e fundamentou uma nova abordagem de aprendizagem na qual está presente o conhecimento conectivo - o Conectivismo. Stefhen Downes (2005) destaca o conhecimento conectivo, defendendo que a aprendizagem ocorre por meio da capacidade do humano de construir uma ampla rede de conexões. As comunidades de prática, redes pessoais ou atividades relacionadas ao trabalho também são meios para a aprendizagem.

No Brasil, entre os estudos referentes a teorias de aprendizagem face ao uso de tecnologias na perspectiva do Conectivismo, destacam-se: Araújo (2010), Foresti e Teixeira (2012), Argolo, Soares Neto e Lima (2013) e Bastos e Biagiotti (2014), entre outros. Portanto ainda são poucos os estudos a respeito de como o estudante aprende num mundo permeado por tecnologias.

Deste modo, neste artigo, procura-se realizar uma reflexão teórica sobre esta abordagem de aprendizagem - Conectivismo - no contexto das tecnologias, estabelecendo relações com outras teorias utilizadas no processo ensino e aprendizagem no âmbito escolar: o Cognitivismo de David Paul Ausubel (1918 - 2008) e o Construcionismo de Seymour Papert. Para isto, inicia-se com uma abordagem das principais ideias desses três autores e posteriormente apresenta-se uma reflexão para a aprendizagem na era digital. 


\section{CONSIDERAÇÕES A RESPEITO DE TEORIAS DE APRENDIZAGEM}

\subsection{As ideias de David Ausubel - a aprendizagem significativa}

O psicólogo americano David Paul Ausubel (1918-2008), contrário à aprendizagem mecânica, foi um representante do Cognitivismo. Para ele, aprender é modificar o conhecimento, ou seja, significa organização e integração do material na estrutura cognitiva. Dessa forma, propôs o conceito da aprendizagem significativa. Ausubel foi um defensor do Construtivismo e sua teoria argumenta que o sujeito constrói novos conhecimentos a partir do seu conhecimento prévio, por meio de elos denominados de pontes cognitivas. Este conhecimento prévio ele denominou de subsunçor. Assim, a aprendizagem significativa ocorre quando uma nova informação ancora-se em conceitos subsunçores já existentes em sua estrutura cognitiva (Moreira; Masini, 1982). Sendo assim, o conhecimento prévio é a base para a ampliação do conhecimento.

Na teoria de Ausubel, o armazenamento de ideias no cérebro é altamente organizado, com relações ocorrendo entre elementos mais antigos e mais recentes, produzindo uma hierarquia conceitual, na qual os elementos mais específicos do conhecimento estão ligados a conceitos mais gerais. $O$ ensino deve ser efetuado programando os assuntos de forma hierárquica, com a estrutura lógica explicitando as relações entre as ideias, ressaltando as similaridades comuns e levando em consideração o conhecimento anterior do estudante. As ideias mais gerais de um conteúdo devem ser apresentadas primeiro e então serem progressivamente diferenciadas em termos de detalhe e especificidade, conforme ilustrado na Figura 1.

Figura 1 - Representação esquemática do modelo de Ausubel

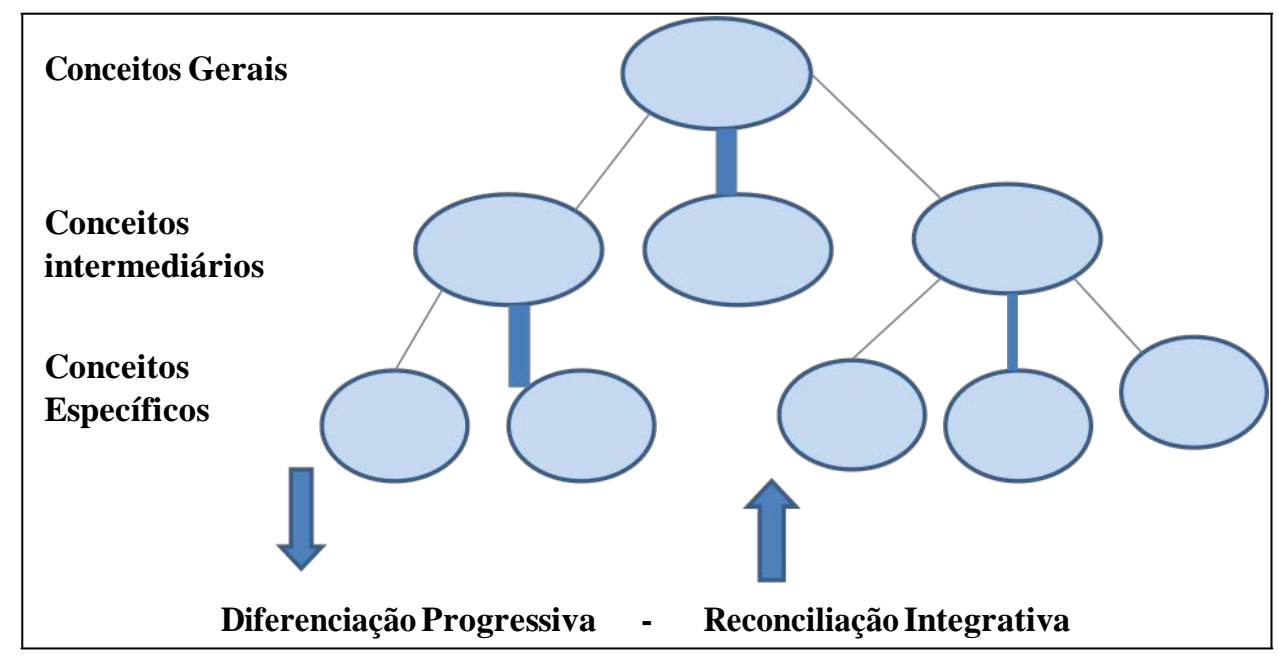

Fonte: Elaborado pelos autores (2014)

Ausubel entende a aprendizagem em uma perspectiva tanto lógica quanto psicológica, destacando que a assimilação de novos conteúdos mobiliza grandes quantidades de conhecimentos prévios do aprendiz.

A essência do processo de aprendizagem significativa é que as ideias expressas simbolicamente são relacionadas às informações previamente adquiridas pelo aluno através de uma relação não arbitrária e substantiva (não literal). Uma relação não arbitrária e substantiva significa que as ideias são relacionadas a algum aspecto relevante existente na estrutura cognitiva do aluno, como, por exemplo, uma imagem, um símbolo, um conceito ou uma proposição. (Ausubel; Novak; Hanesian, 1980, p. 34). 
A aprendizagem significativa implica em ampliar e modificar o conceito já construído pelo sujeito. Assim o conhecimento é construído por meio de interação de novos conceitos aos já existentes, os quais facilitam a compreensão das novas informações dando significado real ao conhecimento adquirido. Porém, para haver aprendizagem significativa existem os seguintes pré-requisitos: a) o estudante estar predisposto a aprender; b) o conteúdo a ser aprendido ter potencial significativo. (Moreira; Masini, 1982).

De acordo com a teoria, a aprendizagem significativa pode se processar tanto por descoberta quanto por recepção. No primeiro caso o estudante deve aprender sozinho, descobrindo algum princípio semelhante ao que acontece na solução de um problema; já no segundo, o estudante pode receber as informações por meio de diálogo e atuar ativamente sobre elas, a fim de relacionar as mais relevantes, em sua estrutura cognitiva.

O matemático e educador americano Joseph Donald Novak (1932 - ) refinou a teoria da aprendizagem significativa acrescentando a ela os mapas conceituais, que podem ser entendidos como uma estratégia facilitadora da aprendizagem significativa. Para ele, os mapas conceituais seriam como uma forma de organizar e representar o conhecimento, a partir da teoria da aprendizagem significativa. Sendo assim, os mapas conceituais reduzem de forma analítica, a estrutura cognitiva subjacente a um dado conhecimento aos seus elementos básicos (Moreira, 1999).

Nesta perspectiva, os mapas conceituais têm por objetivo representar relações significativas entre conceitos na forma de proposições, as quais são constituídas de dois ou mais termos conceituais unidos por palavras para formar uma unidade semântica (Novak; Gowin, 1988). As redes semânticas ou mapas conceituais, por sua vez, são diagramas "constituídos por nós, que representam conceitos, e por linhas rotuladas, que representam as relações entre eles” (Jonassen, 2000, p. 73). Elas são as bases para a elaboração dos hipertextos.

No ensino, o mapa conceitual pode ser um suporte apropriado para a arquitetura de sistemas de hipertexto por possibilitar uma interface atrativa, interativa e fácil de ser utilizada, facilitando a navegação em redes semânticas. O hipertexto pode-se constituir uma ferramenta impulsionadora da aprendizagem, pois o trabalho envolve o estudante na pesquisa e na produção textual de forma não linear. Dessa forma ele estará aprendendo significativamente por meio da descoberta, de acordo com Ausubel. Isso deve-se ao fato do estudante estar ativamente participando do processo ao localizar informações de referência nos "nós” (Lévy, 1993) e fazer ou não uso dela para a elaboração de sua base de dados.

Lévy (1993) destaca que essa atividade pode ocorrer de modo colaborativo e com o uso de tecnologias que possibilitam as conexões. Desta forma pode se constituir numa importante ferramenta para o ensino na era digital. As contribuições de Seymour Papert possuem aspectos comuns a de Ausubel no tocante à aprendizagem: ambos defendem que a aprendizagem deve ocorrer de modo colaborativo e motivada pelo interesse do sujeito aprendente.

\subsection{As ideias de Seymour Papert: o construcionismo}

O matemático e educador Seymour Papert (1928 - ), defensor da utilização do computador como uma ferramenta educacional na aprendizagem, propôs o Construcionismo, uma abordagem que defende que o sujeito constrói o seu próprio conhecimento por intermédio do computador. Suas ideias se originam de um conjunto de princípios de pensadores objetivando aproveitar melhor o uso das tecnologias no ensino. 
Papert (2008) destaca que no construcionismo, a elaboração do conhecimento só acontece quando o sujeito constrói um objeto de seu interesse, seja um desenho, uma imagem, um texto, um mapa ou um programa de computador. Esta construção deve ter vínculo com a realidade do sujeito ou com o local em que ele será produzido e utilizado. O construcionismo implica numa interação estudante-objeto, mediada por uma linguagem de programação, como é o caso do Logo. O produto, resultado do processo, pode ser exibido, visto, externalizado, discutido, examinado, admirado e analisado. Papert (2008) acredita que esta é a principal característica do construcionismo, pois ela permite a construção mental.

Papert e Harel (1991) explicam que o construcionismo, de uma forma sucinta, poderia ser caracterizado como um modo de aprendizado que pede a construção de algo para que se possa compreender o seu funcionamento. Valente (1993) corrobora afirmando que o computador extrapola o caráter de instrumento que ensina o aprendiz, tornando-se uma ferramenta com a qual o estudante desenvolve algo, e, portanto, a aprendizagem ocorre pelo fato de estar executando uma tarefa por meio do computador. Nesta perspectiva, os softwares representados pelas planilhas eletrônicas (Excel, Google), os gerenciadores de bancos de dados (Acess), os mecanismos de busca na Internet (Google, Yahoo, Bing, entre outros), as ferramentas de cooperação e comunicação em rede (e-mail, MSN, Facebook, Skype, Moodle, entre outros) e as linguagens de programação (Java, C++, Delphi, Pascal entre outras), propiciariam ao sujeito ser o promotor de uma ação, sendo a aprendizagem uma consequência.

Papert (1980) faz uma analogia do construcionismo com o processo que ocorre numa comunidade de escola de samba no Brasil. Neste sentido o aprender é espontâneo, auto-motivado, de interesse pessoal e ricamente conectado à cultura popular. Este processo incorporado ao processo pedagógico educativo faria com que sujeitos, com seus interesses e experiências, trabalhassem de modo colaborativo na construção de algo cognitivamente significativo por meio de conexões do novo com aquilo que já sabe, tendo no professor um mediador. A aprendizagem ocorreria num contexto de descobertas, de experiências e novos contatos motivados pelo diálogo, em um ambiente propício. Seria ela resultante da interação do sujeito com o objeto do conhecimento, que não se reduz ao objeto concreto, mas inclui o outro, a família, a escola, o social.

Figura 2 - Elementos essenciais da abordagem construcionista de Papert (2008)

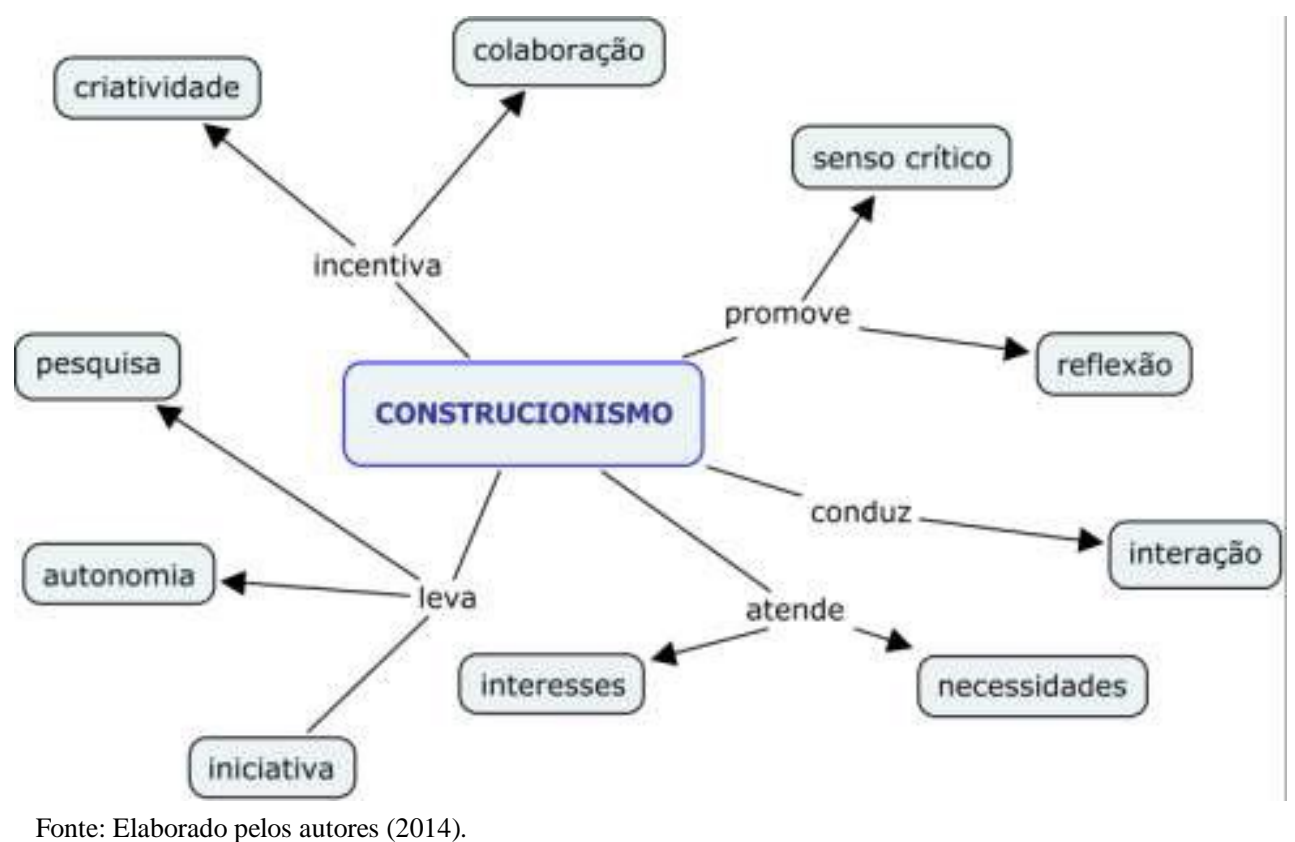

Fonte: Elaborado pelos autores (2014). 
A Figura 2 resume os elementos presentes na abordagem de Papert que, unidas ao uso do computador, configuram uma alternativa ao processo de ensino e aprendizagem num contexto de tecnologias.

\title{
2.3 As ideias de George Siemens e Stephens Downes - o Conectivismo
}

O Conectivismo vem sendo apresentado como uma teoria de aprendizagem para a era digital. Esta teoria emergente trabalha com a visão de que as redes de computadores e as tecnologias digitais viabilizam conexões, apoiadas por artefatos tecnológicos simbólicos (produção cultural e científica da humanidade) armazenados em bases de dados (www) em todas as partes do mundo.

Siemens (2004), em sua teoria, sugere a alteração da visão de produção do conhecimento construtivista para a produção centrada num ambiente de rede, em especial de caráter cibernético, na qual o conhecimento encontra-se distribuído numa rede social de ligações ou conexões. Para o autor, o fenômeno das redes interfere nas formas de interação entre pessoas e as informações e, consequentemente, das pessoas com o conhecimento, que agora passa a ser dependente da conexão entre os vários intervenientes.

A aprendizagem na era digital, de acordo com Siemens (2006), é contínua e também ocorre informalmente por meio da experimentação, diálogo, pensamento e reflexão. Por vezes está relacionada às atividades laborais, tornando importante o aprendizado baseado na experiência e influenciado pelas conexões em rede feitas pelo aprendiz. Essas relações e conexões pessoais, permitidas pela tecnologia estão alterando o modo como as pessoas pensam e agem, consequentemente, como aprendem. Nesse processo, saber como e o que passam a ser complementados pelo saber onde encontrar o conhecimento necessário.

O Conectivismo constitui uma teoria de aprendizagem que ultrapassa as teorias existentes e disseminadas no mundo da educação. Visa atender as necessidades dos nativos digitais e de uma realidade decorrente do desenvolvimento tecnológico e das transformações econômicas, sociais e culturais. Para ele

\begin{abstract}
a aprendizagem é um processo que ocorre dentro de ambientes nebulosos em que os elementos centrais estão em constante mudança - não totalmente sob o controle do indivíduo. Aprendizagem (definida como conhecimento aplicado) pode residir fora de nós mesmos (dentro de uma organização ou de um banco de dados), é focada em conectar conjuntos de informações especializadas, e as conexões que nos permitem aprender mais são mais importantes do que o nosso estado atual de conhecimento. (Siemens, 2004, p. 5-6).
\end{abstract}

Portanto para Siemens (2004) e Downes (2005 e 2007), o Conectivismo, enquanto teoria integra princípios apresentados pelo caos, redes neurais, complexidade e auto-organização. Segundo esta teoria, a aprendizagem é um processo que ocorre numa gama de ambientes dependendo de uma diversidade de opiniões e, não está, necessariamente, sob o controle humano. Derivada desta proposição compreende-se que o conhecimento aplicável pode estar ou situar-se fora do sujeito, podendo estar contido numa organização ou numa base de dados. O foco está na conexão especializada entre as informações. Esta conexão amplia o estado atual do conhecimento, sendo um dos pontos chaves a habilidade de estabelecer conexões entre ideias, áreas e conceitos.

O Conectivismo apresenta alguns pontos teóricos centrais que lhe conferem o caráter de originalidade (Siemens, 2008). Estes pontos seriam o que a distinguem do construcionismo de Papert e do Cognitivismo de Ausubel: 
a) o Conectivismo é a aplicação do princípio das redes para definir tanto o conhecimento como o processo de aprendizagem. O conhecimento é definido como um padrão particular de relações, e a aprendizagem como a criação de novas conexões e padrões por um lado, e por outro, a capacidade de manobrar por meio das redes os padrões existentes;

b) o Conectivismo lida com os princípios da aprendizagem - biológico/neurais conceptuais e sociais/externos;

c) o Conectivismo concentra-se na inclusão da tecnologia como parte da nossa distribuição de cognição e de conhecimento. O conhecimento reside nas conexões que o aprendente cria com outras pessoas ou com fontes de informação, como bases de dados. Dessa forma deve-se sempre manter atualizadas e alimentar estas conexões;

d) enquanto as outras teorias prestam uma atenção parcial ao contexto, o Conectivismo reconhece a natureza fluída do conhecimento e das conexões com base no contexto;

e) compreensão, coerência, interpretação, significado: estes elementos são acentuados no Construtivismo e menos no Cognitivismo. Mas o Conectivismo argumenta que o fluxo rápido e a abundância de informação elevam estes elementos a um patamar crítico de importância.

A Figura 3 ilustra uma síntese do Conectivismo de acordo com as ideias de Siemens e Downes.

Figura 3 - Concepção de Conectivismo segundo Siemens (2008) e Downes (2005)

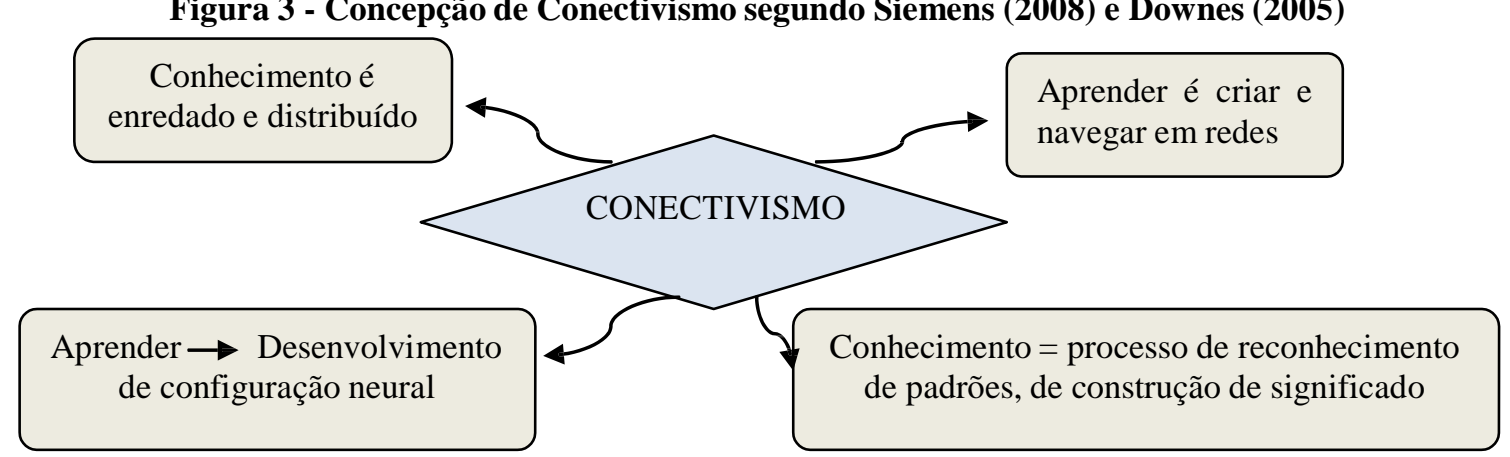

Fonte: Elaborado pelos autores (2014)

\section{A BUSCA DE UMA UNIDADE}

Cronologicamente o Conectivismo é a teoria mais recente, porém possui pontos comuns ao construcionismo e a aprendizagem significativa. Entende-se que o Conectivismo extrapola o caráter intelectual e pedagógico do construcionismo, que por sua vez extrapola e substitui o Cognitivismo de Ausubel.

A partir das ideais de Ausubel, Papert e Siemens estabeleceu-se relações analíticas levando em consideração as compreensões de como o sujeito pode aprender num espaço escolar que atualmente é permeado por tecnologias de informação e comunicação. O quadro 1 apresenta uma síntese dos autores.

Siemens (2004) afirma que a aprendizagem é uma atividade constante na vida humana e é contínua, permanente e fluída, e a tecnologia a potencializa cada vez mais, ligando os indivíduos e conectando-o a diversas áreas. Conexões essas que determinam o fluxo do conhecimento. Assim, é referido que o conhecimento é distribuído por meio de uma rede de conexões e que a aprendizagem consiste na habilidade do aprendiz em conseguir construir e navegar na rede (Downes, 2007). Em contraste com o 
Construtivismo/Construcionismo, em que o humano constrói o seu próprio conhecimento por meio das interações que realiza.

Quadro 1 - Resumo das principais contribuições dos teóricos para o processo da aprendizagem.

\begin{tabular}{|c|c|c|c|}
\hline & Cognitivismo - Ausubel & Construcionismo- Papert & Conectivismo - Siemens \\
\hline 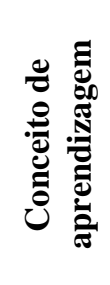 & $\begin{array}{l}\text { A aprendizagem é a } \\
\text { ampliação da estrutura } \\
\text { cognitiva por meio da } \\
\text { incorporação de novas } \\
\text { ideias a ela. }\end{array}$ & $\begin{array}{l}\text { Aprender é } \text { pensar } \\
\text { diferente de antes, é ver o } \\
\text { mundo de outra forma, sob } \\
\text { outros aspectos. } \\
\text { existência Supõe a } \\
\text { alfabetizações. }\end{array}$ & $\begin{array}{l}\text { A aprendizagem é um processo que } \\
\text { ocorre dentro de ambientes } \\
\text { nebulosos; pode residir fora de nós } \\
\text { mesmos; é focada em conectar } \\
\text { conjuntos de informações } \\
\text { especializadas, as quais nos } \\
\text { permitem aprender mais. }\end{array}$ \\
\hline 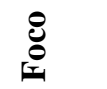 & $\begin{array}{l}\text { Subsunçor } \quad-\quad \text { ideias } \\
\text { âncoras }\end{array}$ & $\begin{array}{l}\text { Inserção do computador no } \\
\text { espaço da sala de aula. }\end{array}$ & Redes conectivas. \\
\hline 递 & $\begin{array}{l}\text { Capacidade de relacionar } \\
\text { o novo com o existente - } \\
\text { interação. }\end{array}$ & $\begin{array}{l}\text { Interação do aprendente } \\
\text { com o computador. }\end{array}$ & $\begin{array}{l}\text { Capacidade do aprendente de } \\
\text { formar conexões e reconhecer } \\
\text { padrões. }\end{array}$ \\
\hline 总 & $\begin{array}{l}\text { Construir conhecimento } \\
\text { relacionando entre si os } \\
\text { conceitos aprendidos ao } \\
\text { encontrar sentido no que } \\
\text { está aprendendo. }\end{array}$ & $\begin{array}{l}\text { Construir conhecimento } \\
\text { quando entendem suas } \\
\text { experiências. }\end{array}$ & $\begin{array}{l}\text { Capacidade de discutir, dialogar e } \\
\text { constantemente retomar. }\end{array}$ \\
\hline 递 & $\begin{array}{l}\text { Organizadores prévios - } \\
\text { pontes cognitivas. }\end{array}$ & $\begin{array}{l}\text { Espaço para as descobertas } \\
\text { a partir das experiências; } \\
\text { Motivação ao diálogo. }\end{array}$ & $\begin{array}{l}\text { Aprendizagem ocorre em rede - por } \\
\text { meio da Conectividade. }\end{array}$ \\
\hline 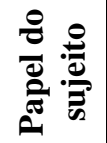 & $\begin{array}{l}\text { Ampliar conhecimento a } \\
\text { partir do já existente. }\end{array}$ & $\begin{array}{lcr}\text { Realizar uma } & \text { leitura do } \\
\text { mundo } & \text { e } & \text { resolver } \\
\text { problemas. } & & \end{array}$ & Nó ativo na rede. \\
\hline
\end{tabular}

Fonte: Elaborado pelos autores (2014).

De posse das informações constante no Quadro 1, verifica-se que o Conectivismo partilha com o construcionismo a ideia de que o conhecimento não é adquirido nem tem existência como se fosse uma "coisa"; difere, no entanto dele, na medida em que também não o entende como propositivo, no sentido cognitivista e de acordo com o processo Piagetiano de adaptação e organização. Para ambos, o conhecimento ocorre literalmente no conjunto das conexões formadas pelas ações e pela experiência ocorridas na escola e também fora dela, por exemplo, por meio de redes colaborativas; pode consistir em parte em estruturas linguísticas, mas na sua essência não está baseado nelas. As conexões formam-se espontaneamente, por um processo de associação natural, e não de construção. O sujeito, de acordo com as teorias, é possuidor de iniciativa e autonomia, e como é responsável por seu conhecimento, é criativo e o processo leva-o a desenvolver a prática da pesquisa. Para tal, essas teorias promoveriam o desenvolvimento crítico e, consequentemente, à reflexão.

O Conectivismo compartilha com o Cognitivismo - a aprendizagem significativa - que o conhecimento seria ampliado ou modificado quando o estudante, ao estabelecer novas conexões, o faz porque tem interesse e porque o objeto de estudo é significativo. As redes semânticas seriam uma estratégia para tornar a aprendizagem significativa ampliando os "nós", estimulando a pesquisa, a iniciativa e o poder de decisão ancorados nos seus conhecimentos prévios. Portanto, as descrições de aprendizagem ocorridas nas redes podem ser contempladas nas estruturas da aprendizagem significativa por meio 
dos mapas conceituais, em que aprender significa aumentar a quantidade de redes. Desta forma, isto também poderia ser utilizado na aprendizagem da era digital.

\section{CONSIDERAÇÕES}

O presente trabalho realizou uma análise reflexiva sobre a teoria da aprendizagem, conhecida como Conectivismo e estabeleceu relações desta com as teorias do Cognitivismo e do Construcionismo, que podem ser aplicadas a aprendizagem na era digital. As três teorias levam em consideração a interação e defendem que a aprendizagem ocorre quando o sujeito está interessado e motivado a aprender. Para elas, a aprendizagem significativa surgiria em oposição à aprendizagem mecânica num processo em que o estudante participa ativamente na elaboração de seu saber. As relações estabelecidas pelo aprendente são essenciais para o aprendizado e elas ocorreriam num contexto de descobertas, de experiências e de novos contatos motivados pelo diálogo, em um ambiente propício para aprendizagem.

Levando em considerações estas confluências, a aprendizagem ocorreria em ambientes formais e informais e de modo colaborativo, cada um aprendendo e ensinando e cada um a sua maneira. A escola não seria mais composta por salas seriadas e nem teria um currículo por disciplina e talvez nem por um espaço físico delimitado. A aprendizagem ocorreria pelo interesse em saber mais e por meio das conexões que o estudante estabeleceria, tendo como ponto de partida os seus conhecimentos prévios. $\mathrm{O}$ desejo de saber mais e estabelecer conexões impulsionaria a aprendizagem, por meio do aumento e atualização das redes estabelecidas pelos sujeitos.

O foco da aprendizagem estaria na rede de conexões permanentes, proporcionadas pela utilização das tecnologias, ancoradas no conhecimento prévio e nas relações já estabelecidas. Aprender na era digital pressupõe um sujeito autônomo, conectivo, criativo, crítico, interativo e reflexivo perante as decisões que necessita tomar ao navegar pela rede. Quanto ao papel do sujeito aprendente, seria um nó na rede, que aprende continuamente ao interagir e estabelecer conexões para compreender o mundo e resolver problemas, ancoradas nos conceitos prévios que constantemente seriam ampliados e atualizados. Ele seria capaz de atuar na sociedade de forma autônoma, derivada da capacidade reflexiva proporcionada pelos ambientes colaborativos. Nesta perspectiva, o conhecimento organizado pelo sujeito hoje, pode constituir-se em fonte de informação para outros, amanhã.

O contexto para a aprendizagem se daria em rede, motivados pelos ambientes de aprendizagem não necessariamente formais, que primam por diálogo, sejam colaborativos, em que as descobertas e as experiências seriam essenciais na ampliação e na manutenção das redes. Por meio delas, o sujeito aprendente compartilharia por meio dos blogs, por exemplo, as informações selecionadas no processo e reflexões oriundas de pesquisas realizadas.

A interação entre o sujeito e o objeto da aprendizagem, promoveria um sujeito autônomo capaz de filtrar as informações necessárias para a construção do saber e relacionar o novo conhecimento com o existente. A (re)construção/ampliação do conhecimento se daria por meio das conexões e seria feita de modo crítico, sendo a experiência a impulsionadora do desenvolvimento dos processos cognitivos.

Finalmente destaca-se o papel do professor neste processo de ensino e aprendizagem com o uso das tecnologias. Ele seria o mediador, aquele que auxiliaria e orientaria o sujeito aprendente na construção, ampliação e manutenção das redes proporcionando espaços reflexivos para a percepção e a apreensão das oportunidades de aprendizagem. Forneceria subsídios necessários para que o sujeito aprendesse a 
encontrar, selecionar e filtrar as informações presentes nas conexões, bem como formas adequadas de organizar e comunicar suas compilações nos espaços de divulgação. $\mathrm{O}$ professor trabalharia na orientação de como, quando e onde obter informações, trabalhando com seu estudante o verdadeiro sentido da pesquisa. Abandonaria o posto de detentor do conhecimento e daquele que transmite o conteúdo da disciplina, prática ainda comum na maioria dos espaços escolares.

\section{REFERÊNCIAS}

ARAÚJO, I. M. T. M. Será possível dissociar o conectivismo do contexto de ensino superior actualmente? Indagatio Didactica, v. 2, n. 2, 2010, p. 104-18.

ARGOLO, E. S.; SOARES NETO, C. S.; LIMA, J. V. Uma abordagem semiótica aplicada a objetos hipermídia educacionais no SBTVD. Renote, v. 11, n. 1, julho, 2013.

AUSUBEL, D. P.; NOVAK, J. D.; HANESIAN H. Psicologia Educacional. $1^{\text {a }}$ ed. Rio de Janeiro: Interamericana, 1980

BASTOS, R. C.; BIAGIOTTI, B. MOOCs: uma alternativa para a democratização do ensino. Renote, v. 12, n. 1, julho, 2014.

DOWNES, S. An Introduction to Connective Knowledge. 2005. Disponível em: <http://www.downes.ca/post/33034.> Acesso em: 16 maio 2014.

. What Connectivism Is. Forum. Online Connectivism Conference. February 1, 2007. pp. 85-91. Disponível em: <http://www.downes.ca/post/38653>. Acesso em: 16 maio 2014.

FORESTI, A.; TEIXEIRA, A. C. Proposta de um conceito de aprendizagem para a era digital. Relatec, v. 11, n. 2, 2012, p. 55-68.

JONASSEN, D. H. Computadores, Ferramentas Cognitivas - Desenvolver o pensamento crítico nas escolas. Lisboa: Porto Editora, 2000.

LÉVY, P. As Tecnologias da Inteligência: O Futuro do Pensamento na Era da Informática. Tradução de Carlos Irineu da Costa. Rio de Janeiro: Editora 34, 1993.

MOREIRA, M. A. Aprendizagem significativa. Brasília: Editora da UNB, 1999.

MOREIRA M A; MASINI, E. F. S. Aprendizagem significativa: a teoria de David Ausubel. Moraes. São Paulo: Moraes, 1982.

NOVAK, J.; GOWIN, D. Aprender a aprender. Tradução de Carla Valadares. Lisboa: Editora Plátanos, 1988.

PAPERT, S. A máquina das crianças: repensando a escola na era da informática. Porto Alegre: Artmed, 2008.

Logo: computadores e Educação. São Paulo: Editora Brasiliense, 1985.

. Mindstorms: Children, computadores e poderosas ideias. New York (NY):

Basic Books, 1980

PAPERT, S; HAREL, I. Constructionism. Norwood: Ablex Publishing Corp., 1991.

PRENSKY, M. Digital Natives, Digital Immigrants. On the Horizon, MCB University Press, v. 9, n. 5, 2001. 
SIEMENS, G. Conectivismo: Uma teoria de Aprendizagem para a idade digital. 2004.

Learning ecology, communities and networks: extending the classroom. 2003. Disponível em: <http://www.elearnspace.org> Acesso em: 20 maio 2014.

. Knowing knowledge, 2006. Disponível em: <http://www.elearnspace.org>. Acesso em: 2 jun. 2014.

. What is the unique idea in connectivism? Elearnspace. 2008 Disponível em:

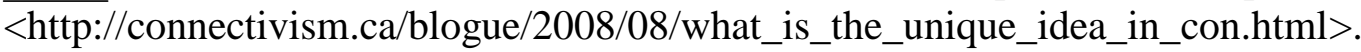
Acesso em: 20 ago. 2014.

VALENTE, J. A. Diferentes usos do computador na educação. In: Computadores e conhecimento: repensando a educação. 1. ed. Campinas(SP): NIED-Unicamp, 1993. 